\title{
Revision of the Genus Phyllotetranychus Sayed with Description of a New Species (Tenuipalpidae) from Egypt
}

\author{
Halawa A.M.*; Amera E. Mesbah** and Azza A. Mohamed ${ }^{* *}$ \\ *Fruit Acarology Dept., Plant Protec. Res. Institute, Agric. Res. Center, Giza, Egypt. \\ ${ }^{* *}$ Cotton and field crops Acarol. Dept., Plant Protec. Res. Institute, Agric. Res. Center,Giza, Egypt.
}

\begin{abstract}
Only one species of the tenuipalpid genus Phyllotetranychus Sayed (Tenuipalpidae), species was recorded on Phoenix dactylifera L. in Egypt. A new species is described (Phyllotetranychus gawadii sp. nov.), in addition to a key of males, females and immature stages are also given.
\end{abstract}

Key words: Acari; Tenuipalpidae; Halawa; Flat mite; Fals spider mites; Phyllotetranychus gawadii sp. nov.

\section{INTRODUCTION}

The family Tenuipalpidae has a worldwide distribution with over 1100 valid species belonging to 38 genera (Ochoa et al., 2012). All species are phytophagous and have shown the potential to cause severe economic damage to agricultural crops, ornamentals, and timber (Baker \& Tuttle 1987, Ochoa \& Salas 1989, Evans et al. 1993 and Childers et al., 2003). Genus Phyllotetranychus has been erected from Egypt when represented by Phyllotetranychus aegyptiacus (Sayed 1938). This genus is characterized by having two segmented palps, full complement of setae, dorsal setae shaped like leaves (broadly palmate), ventral, genital and anal plates not developed (Evans et. al., 1993). Only two species of this genus were reported in the world namely: Phyllotetranychus aegypticus Sayed on date palm (Phoenix dactylifera L.) from Egypt and P. romaine Pritchard and Baker recorded on the blue latan palm (Latania loddigesii Mart.) from Mauritius. The first species (P. aegypticus) is a common and widespread, where it is considered the most significant pest on date palm and other palm leaves in Egypt and many countries (Carpenter and Elmer, 1978). Moreover, this species was re-described by Zaher (1984); while the second species ( $P$. romaine) is not common where it was recorded in few countries and described one time as a new species by Pritchard and Baker (1958). Interestingly, the original descriptions of $P$. aegyptiacus and $P$. romaine did not show the chaetotaxy of legs, furthermore, the taxonomic studies on this genus extremely rare and this might be due to absence of interest. So, the present work aims to describe a new species and revise the genus Phyllotetranychus Sayed in Egypt.

\section{MATERIALS AND METHODS}

A survey was conducted on palm trees throughout all provinces of Egypt. Samples were collected weekly and sent on the same day to the Cotton and field Crops Acarology Department, Plant Protection
Research Institute, Agricultural Research center. Mites were separated by using a fine hair brush under dissecting stereo-microscope, cleared in Nesbitt's solution for a week and mounted on glass slides using Hoyer's medium for examination. The mounted slides were labeled with the necessary data and dried at $40^{\circ} \mathrm{C}$ for one week (Zhang, 2003). (The elevation and longitude/ latitude were recorded for each locality using a hand - held Garmin Global Positioning Device (GPS)). Identification steps were carried out according to Pritchard and Baker (1958), Zaher et al. (1969), Zaher (1986), Mesa et al. (2009), Ochoa et al. (2012). The terminology used in this study follows Lindquist (1985) and Mesa et al. (2009). The measurements were given in micrometers $(\mu \mathrm{m})$. Specimens were deposited in the mite collection of the Agriculture Research Center, Plant Protection Research Institute, the Cotton and field Crops Acarology Department, Dokki, Egypt and the collection of Agric. Zoology, Acarine Divis., Agric. Zool. Dept., Faculty of Agric., Cairo University.

\section{RESULTS AND DISCUSSION}

\section{Family Tenuipalpidae Berlese \\ Subfamily Tenuipalpinae Sayed, 1950 \\ Genus Phyllotetranychus Sayed, 1938.}

Key to the world species of the genus Phyllotetranychus

1. Male with dorsocentral hysterosomal setae $(c l, d l$, e1) all similar; female with first pair of dorsal propodosomal setae $(v 2)$ kidney like or very broad near middle (Fig.1, 2, 3, 4).

- Male with dorsocentral hysterosomal setae ( $c 1$, $d 1, e l)$ very dissimilar; female with first pair of dorsal propodosomal setae elongate-elliptical . P. romaine (Fig. 5)

Key to adult females of the Egyptian species of Phyllotetranychus

1. First pair of propodosomal setae (v2) kidney like 


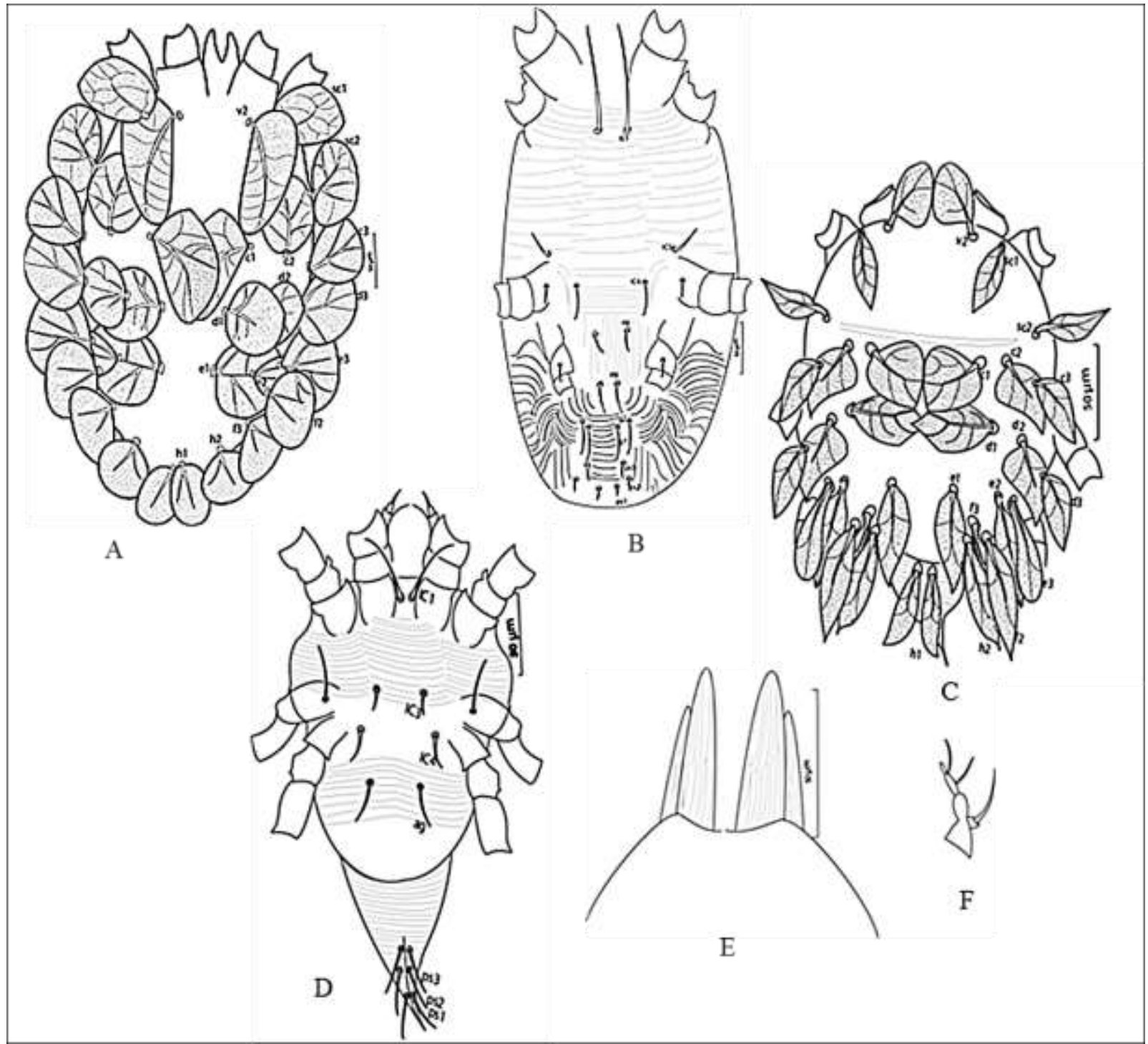

Fig. (1): Phyllotetranychus gawadii Halawa; Mesbah \& Mohamed sp. nov., A- Dorsal female. B- Ventral female. C- Dorsal male. D-Ventral male. E- Rostral. F- Palpus.

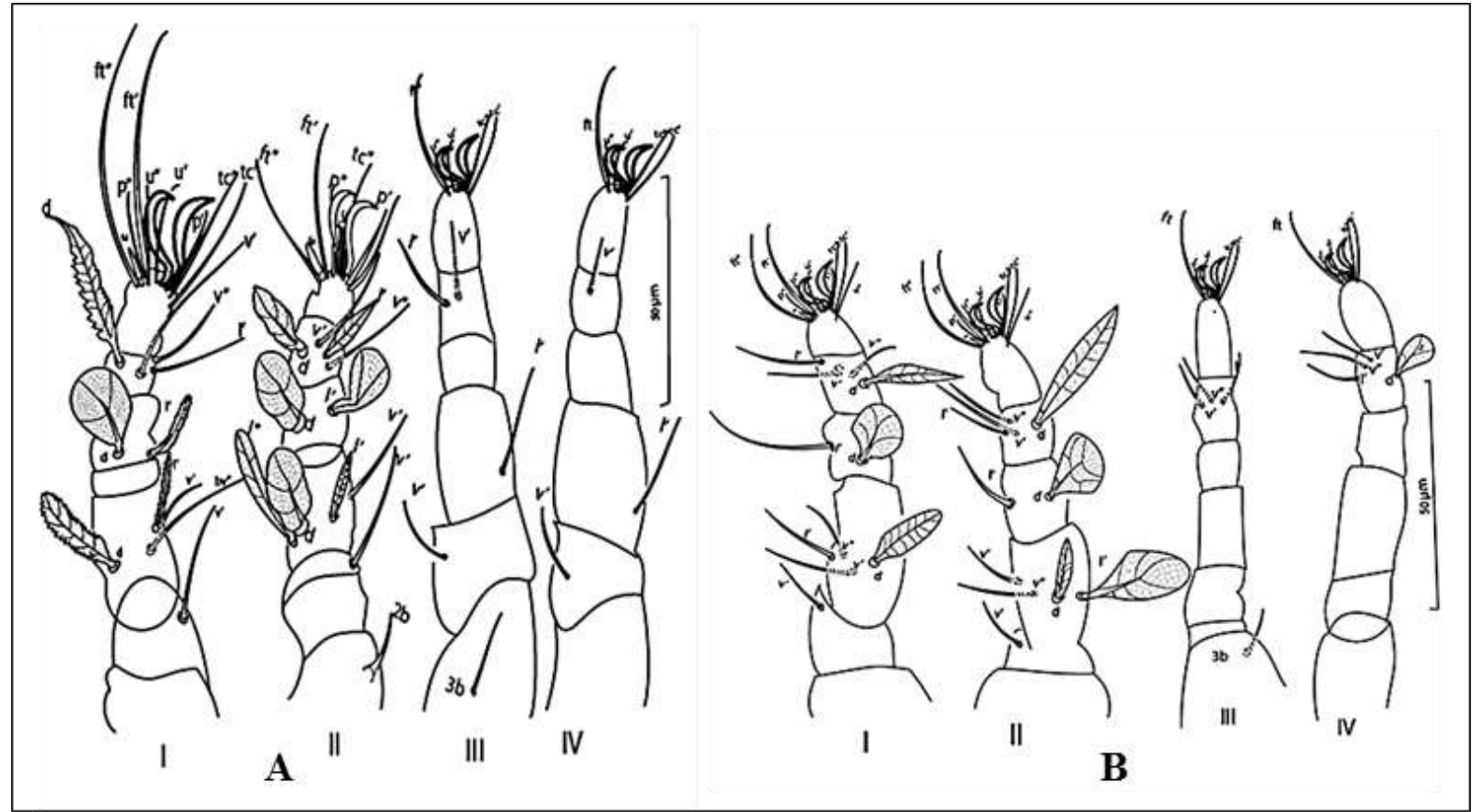

Fig. (2): Phyllotetranychus gawadii Halawa; Mesbah \& Mohamed sp. nov, A- Legs of adult female (leg I; leg II; leg III; leg IV). B- Legs of adult male (leg I; leg II; leg III; leg IV). 


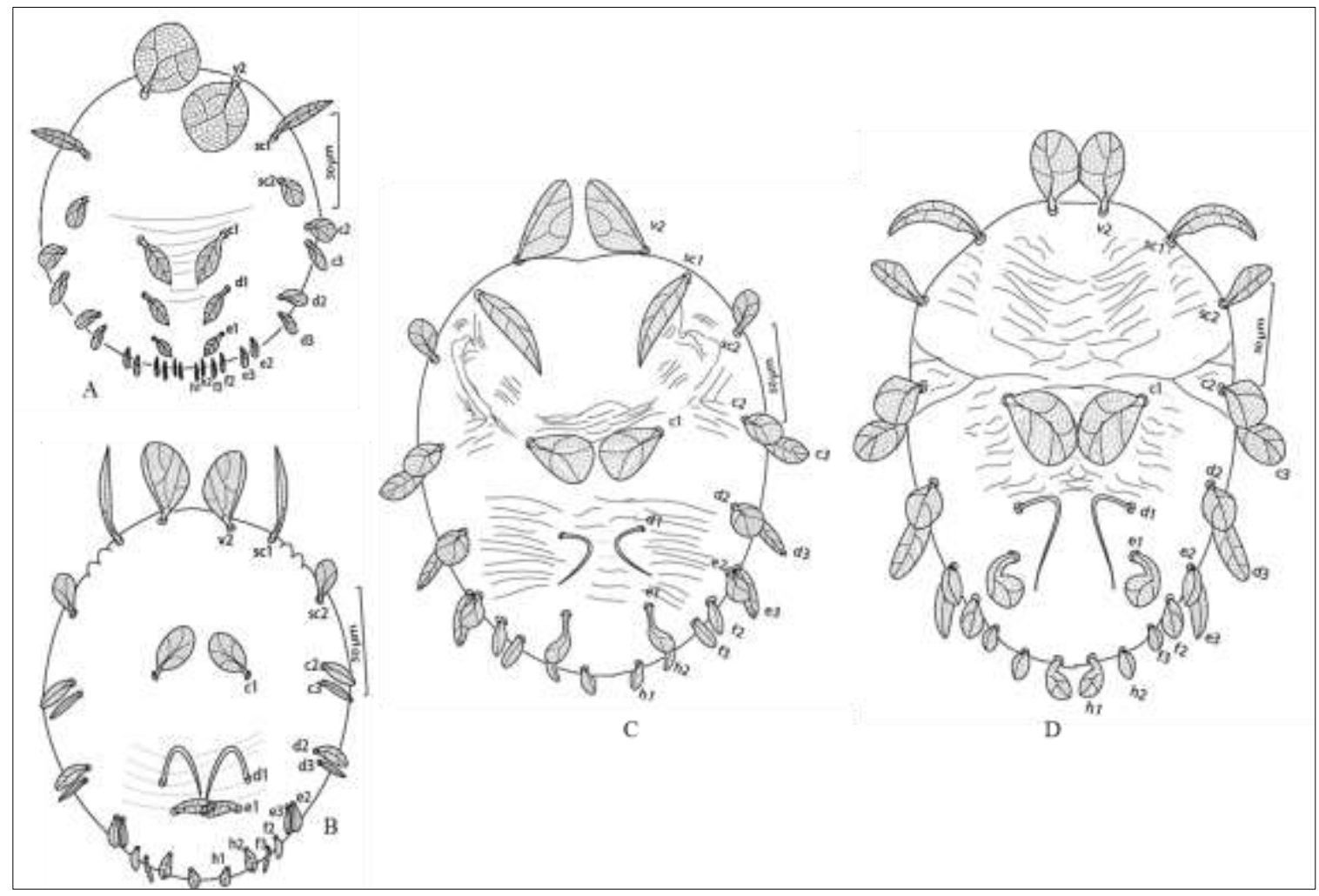

Fig. (3): Immature stages of Phyllotetranychus gawadii Halawa; Mesbah \&Mohamed sp. nov, A- Larva. B- Protonymph. C- Deutonymph. D- Tritonymph.

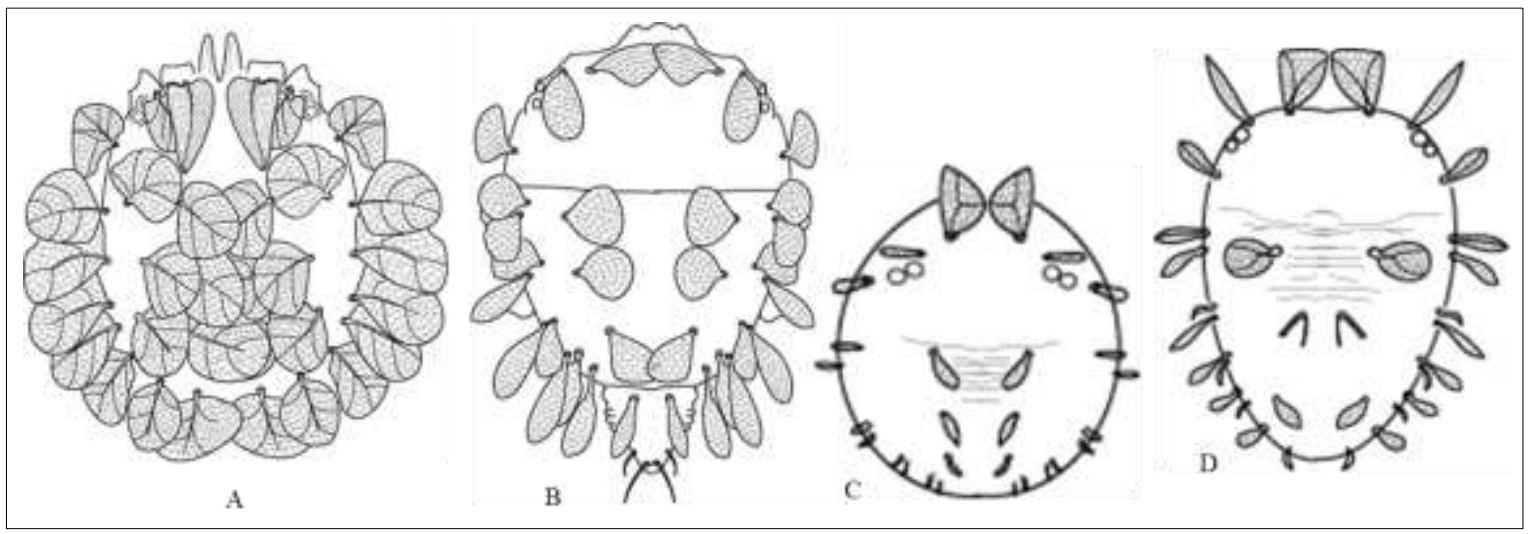

Fig. (4): Phyllotetranychus aegyptiacus after Zaher et al. (1969). A- Dorsal female. B- Dorsal male. C- Larva. D- Protonymph.

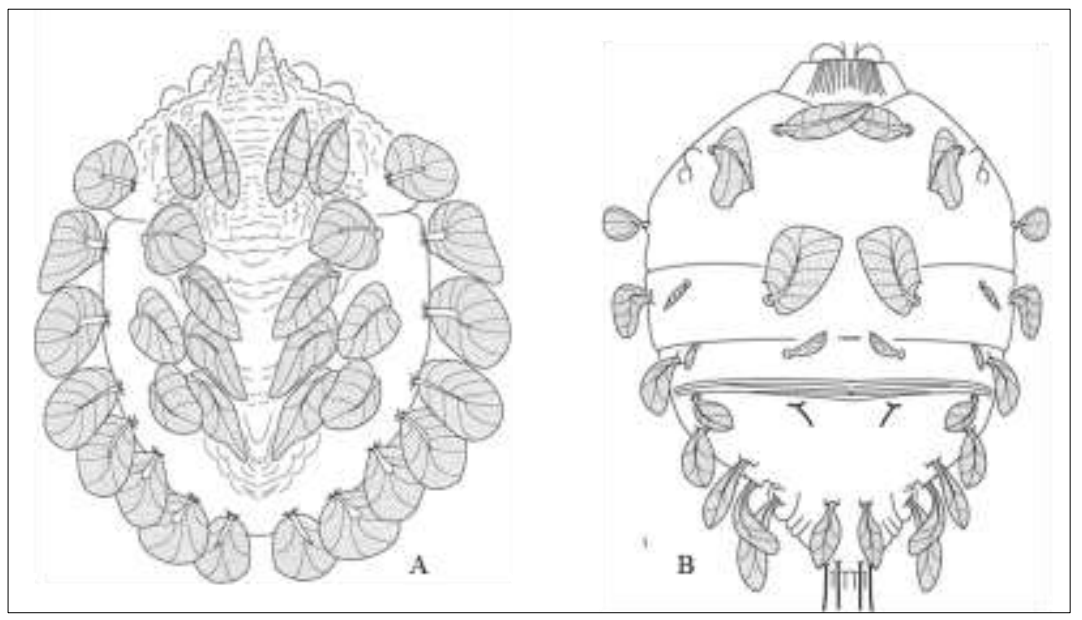

Fig. (5): Phyllotetranychus romaine Pritchard and Baker, after Pritchard and Baker (1958). A- Dorsal female. B- Dorsal male. 
with circular end ....... P. gawadii n. sp. (Fig.1A)

- First pair of propodosomal setae $(v 2)$ very broad near middle and pointed at the end P. aegyptiacus (Fig.4A)

Key to adult male of the Egyptian species of Phyllotetranychus

1. First and second pairs of dorsocentral setae ( $c l-c l$ $\& d l-d l)$ contractual ........... P. gawadii n. sp. (Fig.1C)

- First and second pairs of dorsocentral setae ( $c l-c l$ $\& d l-d l)$ not contractual (Fig.4B)

Key to larva of the Egyptian species of Phyllotetranychus

1. Second pair of propodosomal setae $(S c l)$ extended beyond body margin .......... P. gawadii n. sp. (Fig.3A)

- Second pair of propodosomal setae (Scl) not extended beyond body margin ................ P. aegyptiacus (Fig.4C)

Key to nymphal stages of the Egyptian species of Phyllotetranychus

1. Life cycle with three nymphal stages .............P. gawadii n. sp. (Fig. 3B,C,D)

- Life cycle with one nymphal stage ...............P. aegyptiacus (Fig.4D)

Phyllotetranychus gawadii sp. nov. (Figs. 1, 2, 3)

Diagnosis: Females of Phyllotetranychus gawadii sp. nov. similar to females of Phyllotetranychus aegyptiacus Sayed and Phyllotetranychus romaine Pritchard and Baker in dorsal and ventral but distinguished by some morphological and biological characters

\section{A) Morphological characters:}

The first pair of propodosomal setae ( $v 2)$ kidney like with circulare end in $P$. gawadii sp. nov.; while very broad in the middle with pointed end in $P$. aegyptiacus and elongate-elliptical in $P$. romaine. Dorsocentral setae $(c l, d l, e l)$ in males of $P$. gawadii sp. nov. and P. aegyptiacus similar and strikingly dissimilar in male of $P$. romaine but differentiated between males of $P$. gawadii sp. nov. and $P$. aegyptiacus by the first and second pairs of dorocentral setae $(c l-c l) \&(d l-d l)$ being contactual in $P$. gawadii sp. nov.; while clearly separate in $P$. aegyptiacus. Chaetotaxy of legs completely different in position, number and shape between $P$. gawadii sp. nov and $P$. aegyptiacus.

\section{B) Biological characters:}

The laboratory rearing indicated, three nymphal stages for male and female of $P$. gawadii sp. nov. were recorded with moulting taking place during after quiescent stages between each active stage (Amira Mesbah \& Azza Mohamed, 2015); while Zaher et al. (1969) recorded one nymphal stage in P. aegyptiacus.

\section{Description:}

Female: (holotype) Body globular, reddish; dorsal idiosoma (Fig. 1A) (excluding rostrum) 461 long (458 - 463in 10 paratypes) and $350 \mu \mathrm{m}$ wide (347352). Rostrum barely extending to middle of femur I. Rostral shield covering gnathosoma and bifurcated with two median long lobes extending over the gnathosoma (Fig. 1E). Palpus two segments with sensory peg and two setae on the second segment, proximal segment short with long setae on external side (Fig. 1F). First pair of dorsal propodosomal setae (v2) kidney shape, veined, with circular end and longer than the distance between basses; length: 125 (123 - 127) and wide (from wider part of setae) 46 (45 - 47). Second and third pairs of propodosomal setae $(S c 1 \& S c 2)$ shorter than the first pair (v2) and fanlike with veined pattern; lengths: 77 (70 - 77) \& 57 (5558 ) and wide (from wider part of setae) 57 (55-58) \& 80 (78 - 83). Hysterosoma with 13 pairs of setae, leaflike with veined pattern, nearly of equal length, except the first pair of dosocentral setae $(c 1)$ being the largest $84(82-86)$ and wide( from wider part of setae) $103(100-104)$, these setae distributed as follow: one pair in humeral (c3) 61 (60- 64 ) and wide 65 (63 - 67), three pairs of dorsocentrals $(c 1, d 1, e 1)$ with lengths 84 (82 -86), 65 (63 - 66), 76 (73 - 78) and wide $103(100-104,69(67-70), 80(78-85)$, three pairs of drsosublaterals $(c 2, d 2, e 2)$ with lengths 76 (75 - 78$), 61$ (69 -63), 57 (55 - 58) and wide 75 (73 - 76), $69(68$ - 72), $42(40-44)$ and six pairs of dorsolaterals ( $d 3, e 3, f 2, f 3, h 2, h 1)$ with lengths 73 ( 70 - 74), 69 (68 - 70), $53(52$ - 56), 53 (53 - 55), 50 $(48-52), 61(60-63)$ and wide $80(78-82), 84(82-$ 86), 73 (70 - 75), 76 (73 - 77), 57 (55 - 79), 42 (40 44). Ventral idiosoma with transvers striae on propodosoma and between coxa III; while longitudinal striae presence between coxa IV, all ventral setae smooth; lengths of setae: IC1 113 (110 - 115); IC3, 36 (35 - 37); IC4, 36 (35 - 37); ag 23, (22- 25); pg 33, (31 - 34); g1 36, (34 - 37); g2, 36 (34 - 37); psl, 13 (11 - 17); ps3, 16 (14 - 17) (Fig. 1B). Lengths of legs: I 126 (122-127); II 120 (118 122); III 136 (133 - 137) and IV 132 (130 - 133) (Fig.2A); number of setae on leg segments as follows: coxae 0-1-1-0, trochanters 1-1-1-1, femora 4-4-1-1, genua 2-2-0-0, tibiae 4-4-2-1, tarsi $8(\omega)-8(\omega)-5-5$; femur I with slightly lanceolate serrate setae; while femur II with broadly and slightly lanceolate setae; genu I with broadly and slightly lanceolate setae while genu II with lanceolate and spatulate setae; tibia I with very long slightly lanceolate serrate setae while tibia II with slightly lanceolate setae; tarsi I \& II each with a single sensory rode; claw well developed, 
empodium very short. Leg chaetotaxy as follows: coxae II-III $b$; trochanters I, II, III, IV $v^{\prime}$; femora I, $d$, $v^{\prime}, b v^{\prime \prime}, l^{\prime}$; fe. II $d, v^{\prime}, l^{\prime}, l^{\prime \prime}$; fe. III- IV $l^{\prime}$; genua I-II d, $l^{\prime}$; tibia I-II $d, l^{\prime}, v^{\prime}, v^{\prime \prime}$; ti III-IV $d, v^{\prime}-v^{\prime \prime}$; tarsus I-II $u^{\prime}-u^{\prime \prime}, p^{\prime}-p^{\prime}, t c^{\prime}-t c^{\prime \prime}, f t^{\prime}-f t^{\prime \prime}, \omega$; ta. III-IV $u^{\prime}-u^{\prime \prime}, t c^{\prime}-t c^{\prime \prime}, f t$ (Fig. 2A).

Male: Body triangular, reddish; dorsal idiosoma (Fig.1C) (excluding rostrum) $265 \mu \mathrm{m}$ long (262 - 266) and $181 \mu \mathrm{m}$ wide (178 - 182); rostral shield absent. Palpus two segments with sensory peg and two setae on the second segment, proximal segment short with long setae on external side. Propodosoma with three pairs of setae the first one ( $v 2)$ fanlike, veined (spatulate) with length 43 (40 - 45) and wide (from wider part of setae) 27 (25 - 29) while the second and third pairs $(S c l)$ and $(S c 2)$ are leaflike and elliptical with lengths 40 (3943), 50 (49 - 53) and wide 15 (13 - 14), 13 (13 - 15). Hysterosoma with 13 pairs of leaflike and veined setae except the first pair of dorsocentral fanlike; these setae distributed as follow: one pair of humeral (c3) with length $27(25-30)$ and wide $20(18-21)$, three pairs of dorsocentral contactuals $(c l, d l, e l)$ with lengths: 45 (40 - 45), 56 (55 - 57), 52 (50 - 53) and wide 36 (33 - 38), 29 (27 -30), 20 (19 - 23); three pairs of dorsosublateral setae $(c 2, d 2, e 2)$ with lengths: 43 (40 - 45), 45 (42 - 46), 59 (57 - 59) and wide $29(28-30), 27(25-30), 15(15-17)$. Six pairs of lateral setae $(d 3, e 3, f 2, f 3, h 2, h 1)$ with lengths $40(38-42), 52(50-55), 65(62-66), 65(63-66)$, $63(60-64), 45(42-47)$ and wide $18(16-19)$, 18 (16 - 19), 18 (16 - 19), 18 (16 - 19) 15 (13 - 17), $11(10-12)$.Ventral idiosoma (Fig.1C), transverse striae presence on propodosoma extended to coxae III; while the intercoxae III and IV smooth area, opisthosoma divided into two parts, the upper with transverse striae; while the lower without striae. All ventral setae smooth $I C 1, I C 3, I C 4, a g$, ps3, ps2, ps1 with lengths: 50 (47 - 51), 17 (15 - 19), 22 (20 - 24), 25 (22 - 26), 30 (29 - 33), 27 (25 - 28) and 30 (29 - 33) (Fig. 2D). Lengths of legs: I 98 (97 - 100), II 94 (92 - 96), III $101(100-103)$ and IV 101 (100 - 103); number of setae on leg segments as follows: coxae $0-0-1-0$, trochanters 1-1-0-1, femora 4-4-0-0, genua 2-2-0-0, tibiae 4-4-3-4, tarsi $8(\omega)-8(\omega)-5-5$; femur I with one leaf like setae while femure II with leaflike setae and slightly lanceolate setae; genu I and II with broadly lanceolate setae; tibiae I and II with very long slightly lanceolate setae; while tibiae IV with spatulate setae ; tarsi I \& II each with a single sensory rode; claw will developed, empodium very short. Leg chaetotaxy as follows: coxae III b; trochanters I, II $v^{\prime}$; femora I and II $d, v^{\prime}, v^{\prime \prime}, l^{\prime}$; genua I-II $d, l^{\prime}$; tibia I-II $\mathrm{d}, l^{\prime}, v^{\prime}, v^{\prime \prime}$; ti III $l^{\prime}, v^{\prime}-v^{\prime \prime}$; ti IV $d, v^{\prime}, v^{\prime \prime}, l^{\prime}$; tarsus I-II $u^{\prime}-u^{\prime \prime}, p^{\prime}-p^{\prime}, t c^{\prime}-t c^{\prime \prime}, f t^{\prime}-f t^{\prime \prime}, \omega$; ta. III-IV $u^{\prime}-u^{\prime \prime}, t c^{\prime}-t c^{\prime \prime}, f t$ (Fig. 2B).
Type materials: Holotype female and male (10 paratype females, males) ex (Phoenix dactylifera L.) (Arecaceae ) EGYPT: Giza province, Marutia village, 30॰02'6"N, 31॰12'18"E, January 2015, coll. Azza.

Type depositions.Holotype and 8 paratype females deposited at Plant Protection Research Institute - Agricultural Research Center - Fruit Acarology Department, Dokki, Cairo, Egypt (ARC-PPRI).

Etomology: The new species is named after the third author's father.

Authors communicated with Dr. Ron Ochoa (University of California, San Diego) on the fifth and sixth of may 2015 for confirming the new presented species, who pointed that there are necessitate inquiries must be conducted as follows:

A) What happen when the larva go to protonymph, duetonymph, tritonymph and from them the adults?

B) Make sure protonymph and deutonymph by look at them with the high and low temperature?

C) Make sure ontogeny by observing more setae ventral region in deferent stages from larva to adult?

D) Make sure there is phorate between active stages or not?

Based on the previous enquiries, this species has been reared on controlled high and low temperature in laboratory. The observed results were: A) the new species has three nymphal stages for male and female. B) The moulting takes place directly after the quiescent stages between each active stages on the different temperature degrees. C) Number of immature stages affected by frequent temperature. Moreover, this species differs from $P$. aegyptiacus that has one nymphal stage in male and female, which confirmed by Zaher, et al., 1969. Therefore, the quiescent periods were observed between active stages directly before moulting, which confirmed that, there was no confusion between all stages (larva, protonyph, deutonymph, tritinymph, adult). D) No differences were observed in morphological characters on different frequent temperature degrees, although these differences were observed only in the length time between each stage and other. On the other hand , this study agrees with Evans et.al., 1993, who indicated that ventral, genital and anal plates were not developed in the family tenuipalpidae except, the occurrence of some signs of genital ones (striations on genital place) in the larvae stage of female and the protonymph (aedeagus) in case of the male. Consequently, the ontogenic changes in this species can not be recorded. 


\section{REFERENCES}

Amera, E. Mesbah and Azza, A. Mohamed . 2015. Biology of Phyllotetranychus gawadii (Halawa, Mesbah and Mohamed) ( Acari:Tenuipalpidae) in Egypt. Under publish.

Baker, E. W. and Tuttle, D. M. 1987. The false spider mites of Mexico (Tenuipalpidae: Acari). USDA ARS Technical Bulletin: 1706.

Carpenter, J. B. and Elmer, H. S. 1978. Pests and diseases of the date palm. U.S. Dep. Agric. Handbk., 527: 1-42.

Childers, C. C.; Rodrigues, J. C. V. and Welbourn, W. C. 2003. Host plants of Brevipalpus californicus, B. obovatus, and B. phoenicis (Acari: Tenuipalpidae). Exp. \& Appl. Acarol., 30: 29-105.

Evans, G. A.; Cromroy, H. L. and Ochoa, R. 1993. The Tenuipalpidae of Honduras (Tenuipalpidae: Acari). Florida Entomologist, 76 (1):126-155.

Lindquist, E. E. 1985. Anatomy, phylogeny and systematics. In: Helle, W. \& Sabelis, M.W. (Eds.), Spider mites, the biology, natural enemies and control. Elsevier, Amsterdam, 1A, pp. 272- 418.

Mesa, N. C.; Ochoa, R.; Welbourn, W.; Calvin Evans, G. A. and Moraes, G. J. 2009. A catalog of the Tenuipalpidae (Acari) of the world with a key to the genera. Zootaxa, 2098: 1-185.

Ochoa, R. and Salas, L. A. 1989. The genus Brevipalpus in Costa Rica (Acari:

Tenuipalpidae). International Journal of Acarology, 15(1): 21-30

Ochoa, R.; Beard, J.; Bauchan, G.;Trice, M.; Redford,
A.;Walters, T. and Mitter, C. 2012. Flat Mites of the World. http://idtools.org/id/mites/flatmites /about_authors.php.

Pritchard, A. E. and Baker, E. W. 1958. The false spider mites (Acarina: Tenuipalpidae). University of California Publications in Entomology, 14(3): 175-274.

Sayed, M. T. 1938. Sur une nouvelle sous-famille et deux nouveaux genres de Tetranyques (Acariens). Bull. Mus. Hist. Nat. Paris, 10: 601-610.

Sayed, M. T. 1950. Description of a new genus and two new species of the family Tenuipalpidae. Proceedings of the 8th International Congress of Entomology, 1018-1021.

Zaher, M. A. 1984. Survey and Ecological studies on phytophagous, predaceous and soil mites in Egypt. Phytophagous mites in Egypt PL. 480 programe U.S.A. project No. EG. ARS, 30. Grant No. FGEG- 139.

Zaher, M. A.; Wafa, A. K. and Yousef, A. A. 1969. Biological studies on Raoiella indiea Hirst and phyllotetranychus aegyptiacus sayed infesting date palm trees in U.A.R. (Acarina: Tenuipalpidae). Z. Angew. Entomol., 63: 406-411.

Zaher, M. A. 1986. Phytophagous mites in Egypt. PL.480 Programme U.S.A. Project No. EG-ARS30. Grant No. FG-EG, 228 pp.

Zhang, Z. Q. 2003. Mites of Greenhouses: Identification, Biology and Control. Centre of Agriculture and Biosciences International Publishing, Wallingford, United Kingdom, xii +244 pp. 